\title{
Effect of Fiber Treatment Condition and Coupling Agent on the Mechanical and Thermal Properties in Highly Filled Composites of Sugarcane Bagasse Fiber/PP
}

\author{
José Alexandre Simã ${ }^{a, b, c *}$, Vitor Brait Carmona ${ }^{a, b}$, José Manoel Marconcini ${ }^{a}$, Luiz Henrique
}

Capparelli Mattoso $^{a}$, Soren Talbro Barsbergc, Anand Ramesh Sanadic

\author{
${ }^{a}$ National Laboratory of Nanotechnology for Agribusiness - LNNA, Embrapa Instrumentation, \\ São Carlos, SP, Brazil \\ ${ }^{b}$ Graduate Program in Materials Science and Engineering - PPG-CEM, Federal University of \\ São Carlos-UFSCar, São Carlos, SP, Brazil \\ ${ }^{c}$ Department of Geosciences and Natural Resource Management, Faculty of Science, University of \\ Copenhagen, Denmark
}

Received: October 8, 2015; Revised: January 19, 2016; Accepted: April 26, 2016

\begin{abstract}
This paper reports on a study of highly filled composites of polypropylene (PP) and $75 \%$ by weight sugarcane bagasse fiber with and without alkali treatment and with and without coupling agent (SEBS-gMA). Composites were prepared using a Rheomix600 mixer connected to a HAAKE torque rheometer. The thermal and mechanical behavior of these composites were investigated by thermogravimetry (TGA), differential Scanning Calorimetry (DSC), flexural tests, impact tests and scanning electron microscopy. Scanning electron microscopy (SEM) images taken from sugarcane bagasse fibers showed enhancements in the fiber's surface topography after the surface treatment process. The FTIR, TGA and SEM results for the fibers showed that the alkali treatment modified the fiber surface as well as the chemical composition. The impact test results showed a good potential of SEBS-g-MA as coupling agent and impact modifier in highly filled composites, increasing by more than $100 \%$ the impact strength of the composite as compared to those without the coupling agent. Scanning electron microscopy showed that addition of coupling agent improved the interfacial adhesion between the fibers and polypropylene.
\end{abstract}

Keywords: Highly filled composites, Interfacial compatibilizers, Sugarcane bagasse fiber

\section{Introduction}

Natural fibers are an interesting alternative as filler of polymer matrices, most of the prior work on lignocellulosic fibers in thermoplastics has concentrated on wood-based flour or fibers, and significant advances have been made by a number of researchers ${ }^{1-5}$. They not only reduce the final cost of the material, but also act as reinforcement by increasing the mechanical properties. The main advantages of such fibers are their good mechanical performance, low cost, renewability, biodegradability and relatively low machine abrasion compared to glass fibers ${ }^{6}$. Plant fibers are mainly composed of cellulose, hemicellulose, lignin, pectin, waxes and water soluble substances, with cellulose, hemicellulose and lignin as the basic components with regard to the physical properties of the fibres? ${ }^{7}$. Several lignocellulosic materials are used as reinforcement in thermoplastic composites, including fibers of sugarcane, banana, jute, ramie, flax, pineapple, curauá, sisal, cotton, coir, luffa cylindrical ${ }^{8}$. The types of fibers that can be used depend on the availability of the fibers and properties needed for the product.

In general, the amount of fibers or fillers being used is generally limited to about $60 \%$ and below by weight of fibers in the thermoplastics ${ }^{9}$, such as wood plastic composites (WPC). WPC are used extensively throughout the world in both the furniture industries and building such as decking and siding ${ }^{10}$. In the WPC that are on the market currently, wood flour used, more often than fibers ${ }^{11}$. One reason for not utilizing fibers to a larger extent as reinforcement in plastics can be related difficulties in continuous processing is the low density of the fibers during feeding, blending, in melt blends equipments ${ }^{11}$. However, it is possible to obtain materials similar to WPC using high contents of lignocellulosic fibers (up to $60 \%$ ). In some studies fiber filled composites, the use of different types of lignocellulosic fibers (kenaf, jute) shows a greater reinforcement than wood flour ${ }^{12-15}$. To produce high fiber content composites there are many challenges, including, an effective transfer of stress the fiber/matrix interface, whereas that linear polymer chains act more as a binder and adhesive between the fibers?

One limitation of lignocellulosic fibers used as reinforcement is the poor interfacial adhesion between polar-hydrophilic fibers and nonpolar-hydrophobic polymers ${ }^{16}$. Various surface treatment methods as well as coupling agents and compatibilizers such as maleic anhydride grafted polymers, silane, alkali treatment and etc have been used to increase the compatibility between natural fibers and thermoplastic matrices, thereby enhancing the composites performance ${ }^{5,17}$.

In the previous study, $\mathrm{NaOH}$ solution was used to modify sisal fibers and bagasse fibers surface. Scanning electron microscopy revealed that the fibers were well dispersed in the matrix. In addition, it was found that the fibers and matrices interacted strongly ${ }^{6,18}$. In an another recent study, flax fibers were surface treated to increase the effectiveness of the compatibilizer and also to make the fibers more compatible with the PP matrix and lower water absorptions was reported when alkali surface treatment was used ${ }^{19}$. 
Styrene-ethylene-butylene-styrene copolymer grafted with maleic anhydride (SEBS-g-MA) was also employed as a coupling agent in the composite preparation. Because the MA segment of the copolymer can react with the hydroxyl groups $(\mathrm{OH})$ on the fiber surface. In addition, the SEBS-gMA has a good entanglement with the PP phase, because the SEBS is able to diffuse into the PP phase under micelle formation ${ }^{20}$.

The present work evaluated the potential of sugarcane bagasse fiber as filler in high fiber content (75\%) composites using PP as matrix and the use of SEBS-g-MA as the coupling agent and impact modifier. Some of the fibers were alkali treatment on the surface of the fiber, to try and improve adhesion fibers/matrix on the mechanical, thermal and morphological properties as compared to untreated fibers.

\section{Experimental}

\subsection{Materials}

The fibers used in this study were kindly supplied by EDRA Ecosistema Ltda (Brazil) and the sodium hydroxide $(\mathrm{NaOH})$ was purchased from Synth, Brazil. The polypropylene (PP) was a homopolymer - H 201 with a melt flow index of $20 \mathrm{~g} / 10 \mathrm{~min}$ (Braskem, Brazil). A maleic anhydride-grafted poly (styrene-ethylene/butyldienestyrene) (SEBS-g-MA), (Kraton FG1901X, Kraton Polymers, USA), grafted with 1.84 wt.\% maleic anhydride, composed of $70 \mathrm{wt} . \%$ of ethylene-butylene block and 30 wt.\% of styrene block and and its melt flow index value of $22 \mathrm{~g} / 10 \mathrm{~min}$ (at $230{ }^{\circ} \mathrm{C}$ and $5 \mathrm{~kg}$ load), was used as a coupling agent.

\subsection{Treatment of sugarcane bagasse fibers}

Sugarcane bagasse was treated with $1 \%$ sodium hydroxide solution (at $60^{\circ} \mathrm{C}, 1 \mathrm{~h}$ ). The fibers were then washed with distilled water to remove excess $\mathrm{NaOH}$ until neutral $\mathrm{pH}$ and subsequently dried at $80^{\circ} \mathrm{C}$ to constant weight.

\subsection{Preparation of composites}

The PP, sugarcane fibers and SEBS-g-MA compositions were blended in a Rheomix 600 mixer connected to a HAAKE torque rheometer at $180^{\circ} \mathrm{C}$ and $50 \mathrm{rpm}$ for 10 min. Test samples for mechanical testing were compression molded. The mold temperature was $190^{\circ} \mathrm{C}$ and the pressure was about $10 \mathrm{MPa}$. The nomenclature and composition of samples tested are given in Table 1.

\subsection{Fiber characterization}

FTIR allows the measurements of variations in the fibers composition after chemical treatment. The chemical structures of the surface of original fibers and pre-treated fibers were evaluated by FTIR spectrophotometer (Perkin Elmer Spectrum 1000). Thermal stability of the fibers was evaluated by thermogravimetry where dried fibers were tested in a thermogravimetric analyzes (TGA) in a TA Q500 thermal analyzer (TA Instruments, USA). The samples were heated from 25 to $600^{\circ} \mathrm{C}$ in air flowing at $60 \mathrm{mLmin}^{-1}$ at a heating rate of $10^{\circ} \mathrm{C} \mathrm{min}^{-1}$. Scanning Electron Microscopy (SEM) to observe the surface of the fibers (JEOL JSM-6510 series), operating at $10 \mathrm{kV}$ was used.

\subsection{Composites characterization}

Five Specimens were prepared for flexural testing (three point bending) according to ASTM D790 standard, and tested using an EMIC DL3000 universal testing machine with the crosshead speed of $1 \mathrm{~mm} \mathrm{~min}^{-1}$ and a support span of $60 \mathrm{~mm}$. Notched impact tests were performed following the ASTM D256, using Tinius Olsen (Model IT504) impact testing machine, using six specimens. Differential Scanning Calorimetry (DSC) measurements of composites were performed in a DSC Q-100 (TA Instruments, USA). The samples ( $4 \mathrm{mg}$ ) were first heated to $220^{\circ} \mathrm{C}$ at $20^{\circ} \mathrm{C} / \mathrm{min}$ and then held isothermally for 1 minute in a nitrogen atmosphere. The samples were then cooled at $10{ }^{\circ} \mathrm{C} / \mathrm{min}$ to collect crystallization data. The melting temperature $\left(\mathrm{T}_{\mathrm{m}}\right)$, crystallization temperature $\left(\mathrm{T}_{\mathrm{c}}\right)$, fusion enthalpy $\left(\Delta \mathrm{H}_{\mathrm{m}}\right)$ and crystallinity index $\left(\mathrm{X}_{\mathrm{C}}\right)$ were determined. The crystallinity index $\left(\mathrm{X}_{\mathrm{C}}\right)$ was calculated according to Eq. $1^{21}$ :

$$
X_{c}(\%)=\frac{\Delta H_{\exp }}{\Delta H_{0} \times f} \times 100
$$

Where $\Delta \mathrm{H}_{\exp }$ is fusion enthalpy $(\mathrm{J} / \mathrm{g})$ determined by DSC measurement, $\Delta \mathrm{H}_{0}$ is theoretical enthalpy of the completely crystalline polymer, which is $165 \mathrm{~J} / \mathrm{g}$ for $\mathrm{PP}^{22}$ and the percentage by weight (\%wt) of $\mathrm{PP}$ is given by the $\operatorname{term} f$.

Scanning Electron Microscopy JEOL (JSM-6510 series), was used to evaluate the fracture surface of sample to obtain insights of the interfacial adhesion between PP and the sugarcane bagasse fiber and the mode of failure of the composite. The samples were deposited on carbon tape, and a thin layer (ca. $15 \mathrm{~nm}$ ) of gold was sputtered on the surface.

Table 1: Composition of the studied formulations.

\begin{tabular}{lcccc}
\hline Sample & PP(wt \%) & Pre-Treatment & SEBS-g-MA(wt \%) & Fiber content(wt\%) \\
\hline PPF & 25 & none & - & 75 \\
PPFN & 25 & NaOH & - & 75 \\
PPFS & 18 & none & 7 & 75 \\
PPFNS & 18 & NaOH & 7 & 75 \\
\hline
\end{tabular}




\section{Results and discussion}

\subsection{Sugarcane bagasse fiber characterization}

Figure 1 shows the normalized FTIR spectra of the treated and untreated fibers. The peak occurring at around $3330 \mathrm{~cm}^{-1}$ corresponds to hydrogen bonded O-H stretching ${ }^{23}$ and the increase in the peaks intensity after alkali treatment could be attributed to the major number of exposed $\mathrm{O}-\mathrm{H}$ groups from the fibers surface due to possible extraction of hemicellulose, lignin and other extractives, which resulted in higher hydrophilic character in the fibers. The peak at about $2900 \mathrm{~cm}^{-1}$ result from $\mathrm{C}-\mathrm{H}$ stretching vibration. The absorption bands at 1727 and $1604 \mathrm{~cm}^{-1}$ which can be ascribed to vibrational stretching of unconjugated carbonyl groups $(\mathrm{C}=\mathrm{O})$, mainly due to hemicellulose and to conjugated carbonyl present in the lignin, respectively. The reduction in the absorption of carbonyl region could be attributed to the removal of hemicelluloses during alkaline treatment ${ }^{23}$. In addition, the absorption intensity at $1237 \mathrm{~cm}^{-1}$ assigned to $\mathrm{C}-\mathrm{O}$ stretching of acetyl groups in the hemicellulose decreased with alkaline treatment. The peak at $1030 \mathrm{~cm}^{-1}$, corresponding to $\mathrm{C}-\mathrm{O}$ stretching of hemicellulose and lignin. These results suggest a reduction in the hemicellulose and lignin content following alkaline treatment of the fibers, as reported previously study ${ }^{24}$.

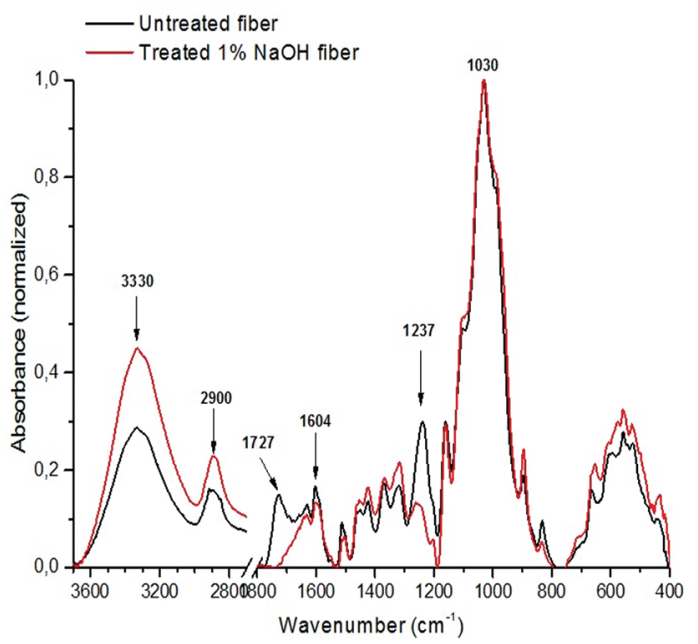

Figure 1: FTIR spectra of the untreated and treated sugarcane bagasse fibers.

The thermogravimetric analysis (TGA) of the treated and untreated fibers is shown in Figure 2. In addition, Table 2 shows the initial degradation temperatures $\left(\mathrm{T}_{\text {onset }}\right)$ and maximum decomposition temperature $\left(\mathrm{T}_{\mathrm{dmax}}\right)$ values of fibers. Both curves show that the decomposition of the fibers began at around $260^{\circ} \mathrm{C}$. The stage from 40 to $150^{\circ} \mathrm{C}$ was due to moisture evaporation. The fibers degraded in two stages. The first transition (the temperature range of the decomposition was from 190 to $400^{\circ} \mathrm{C}$ ) was related to the degradation of cellulosic substances, such as hemicellulose and cellulose $\mathrm{e}^{24}$. The second stage $\left(400-469^{\circ} \mathrm{C}\right)$ of the decomposition was due to the degradation of non-cellulosic materials in the fibers ${ }^{24}$. The TGA results indicate that the alkali treatment did not change the fibers thermal behavior significantly. It is can be explain in terms of amount of lignin, which works as a strong adhesion component between the fibers, and difficult of the penetration of alkaline solution into these areas ${ }^{25}$. The DTG result seems to confirm that the lignin was not removed efficiently by alkaline solution, once the peak around $400^{\circ} \mathrm{C}$ is related mainly to the breaking of the chemical bonds of the lignin present in the fiber ${ }^{25}$. However, there was a decrease in the amount of hemicellulose, which is more susceptible to thermal degradation.

The surface morphology of sugarcane fibers were observed through scanning electron micrographs (Figure 3 ). The Figure 3a shows a superficial layer of extractives on the untreated fiber. On the other hand, the surface of the treated fiber (Fig. 3b) has no such layer, it is can be attributed to the removal of hemicellulose and others extractives.

\subsection{Composites thermal properties}

Thermal properties of pure PP and their composites were investigated by DSC and the results are shown in Table 3. The crystallinity of PP in all the composites were about the same, except in the sample with treated fiber and coupling agent (PPFNS). It must be noted that due to the small amount of PP in the samples and also the small samples sizes for the $\mathrm{DSC}^{26}$. The PPFNS sample had a larger amount of SEBS-g-MA and treated fibers and this can also affect the amount of crystallinity being measured. Further studies need to be conducted to determine the right reasons.

\subsection{Composites mechanical properties}

Mechanical properties such as flexural modulus, flexural strength and impact strength of composites were evaluated, and results are presented in Table 4.

Figure 4 shows the increase of the impact strength in the samples containing SEBS-g-MA. The results show a great potential of SEBS-g-MA as coupling agent and impact modifier in highly filled composites. On the other hand, flexural modulus and flexural strength did not get achieve the values for the pure PP suggestive poor stress transfer. The torque rheometer with low mixing speed and high pressure for to mold the boards can explain this result. Sanadi and Caufield ${ }^{9}$ obtained good results of bending using lower pressures than those used in this work and using a thermokinetic mixing.

\subsection{Morphological analysis}

The fracture surface of the composites with $75 \mathrm{wt} \%$ sugarcane bagasse fibers, untreated and treated, with and without coupling agent are shown in Figure 5. In Figures 5a and $5 \mathrm{~b}$ of the composite without coupling agent the cellulose fibers were easily visible. On the contrary, the overview micrograph of the composite with SEBS-g-MA coupling agent, Figures $5 \mathrm{c}$ and $5 \mathrm{~d}$, showed that despite the fibers look more covered, even more for the composite with treated fibers and coupling agents, this is not reflected in better properties, thus the interface the composite interface can be considered poor, 

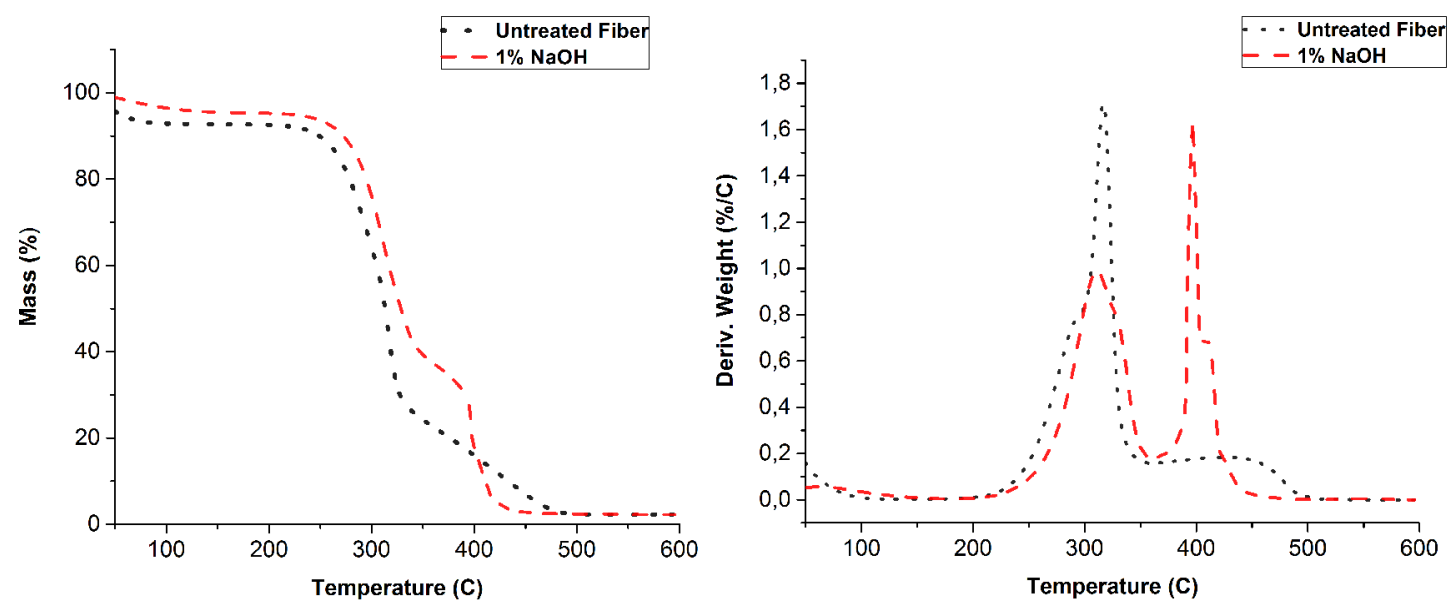

Figure 2: TG and DTG curves of the untreated and treated sugarcane bagasse fibers.

Table 2: Initial degradation temperatures $\left(\mathrm{T}_{\text {onset }}\right)$ and maximum decomposition temperature $\left(\mathrm{T}_{\mathrm{dmax}}\right)$ of the untreated $(\mathrm{F})$ and treated fibers (FN) obtained from TGA.

\begin{tabular}{lcc}
\hline Sample & $\mathrm{T}_{\text {onset }}\left({ }^{\circ} \mathrm{C}\right)$ & $\mathrm{T}_{\mathrm{dmax}}\left({ }^{\circ} \mathrm{C}\right)$ \\
\hline $\mathrm{F}$ & 258 & 317 \\
$\mathrm{FN}$ & 260 & 310 \\
\hline
\end{tabular}

possibly due voids in defects, ineffective mixture in torque rheometer due low speed rotation compared to thermokinetic mixing used in Sanadi and Caufield 9 .

\section{Conclusion}

This study showed that by using the torque rheometer it was possible to process highly filled composites and valuable information before the large-scale processing but the high standard deviations in the mechanical properties suggest that the dispersion of the fibers could be improved by further processing. For the fibers, the TGA results indicate that the alkali treatment did not significantly change the fibers thermal resistance. The FTIR results suggest a reduction in the hemicellulose and lignin content following alkaline treatment of the fibers. Scanning electron microscopy of the fibers surface showed that a layer of extractives was removed after the alkaline treatment. For the highly filled composites the DSC results indicate that due the small amount of PP in the composites, it was difficult to obtain the precise data. Impact testing showed that the SEBSg-MA is a good impact modifier, increasing by more than $100 \%$ the impact strength. Scanning electron microscopy of the fracture surface of the composites revealed a poor interface between the fiber and the polypropylene on the composites without coupling agent, on the other hand, on the composites with coupling agent, the SEBS-g-MA improve that interface. Sugarcane bagasse fibers have potential for application in highly filled composites", however, at this stage further studies need to be conducted on these new materials to evaluate properties such as toughness, creep, etc.

\section{Acknowledgements}

The authors wish to thanks Conselho Nacional de Desenvolvimento Científico e Tecnológico (CNPq/Brazil) and Coordenação de Aperfeiçoamento de Pessoal de Nivel Superior (Capes/Brazil) for financial support. And also, the financial and technical support of EMBRAPA and DEMA/UFSCar.

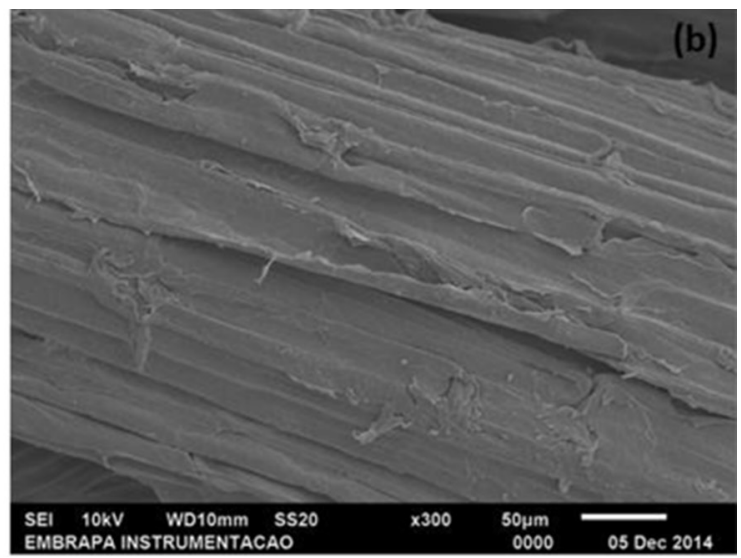

Figure 3: SEM image of sugarcane bagasse fibers: (a) untreated (b) after treatment. 
Table 3: Thermal behavior of the samples obtained from DSC.

\begin{tabular}{|c|c|c|c|c|}
\hline Sample & $\begin{array}{c}T_{m} \\
\left({ }^{\circ} \mathrm{C}\right)\end{array}$ & $\begin{array}{c}T_{c} \\
\left({ }^{\circ} \mathrm{C}\right)\end{array}$ & $\begin{array}{c}\Delta H_{m} \\
\left(J g^{-1}\right)\end{array}$ & $\begin{array}{l}X_{C} \\
(\%)\end{array}$ \\
\hline PP & 164 & 119 & 93.2 & 56 \\
\hline PPF & 163 & 121 & 22.7 & 54 \\
\hline PPFN & 164 & 125 & 21.6 & 52 \\
\hline PPFS & 163 & 119 & 16.1 & 54 \\
\hline PPFNS & 162 & 121 & 14.8 & 50 \\
\hline
\end{tabular}

Table 4: Mechanical properties of the samples.

\begin{tabular}{|c|c|c|c|}
\hline Sample & Flexural modulus (GPa) & Flexural strength $(\mathrm{MPa})$ & Impact strength $(\mathrm{J} / \mathrm{m})$ \\
\hline PP & $1.3 \pm 0.3$ & $37.1 \pm 2.6$ & $26.0 \pm 2.0$ \\
\hline PPF & $1.1 \pm 0.5$ & $18.7 \pm 5.3$ & $17.6 \pm 3.0$ \\
\hline PPFN & $0.3 \pm 0.2$ & $10.6 \pm 4.0$ & $25.5 \pm 2.1$ \\
\hline PPFS & $0.6 \pm 0.3$ & $25.1 \pm 7.0$ & $44.9 \pm 5.8$ \\
\hline PPFNS & $0.5 \pm 0.3$ & $21.4 \pm 6.8$ & $57.4 \pm 3.1$ \\
\hline
\end{tabular}

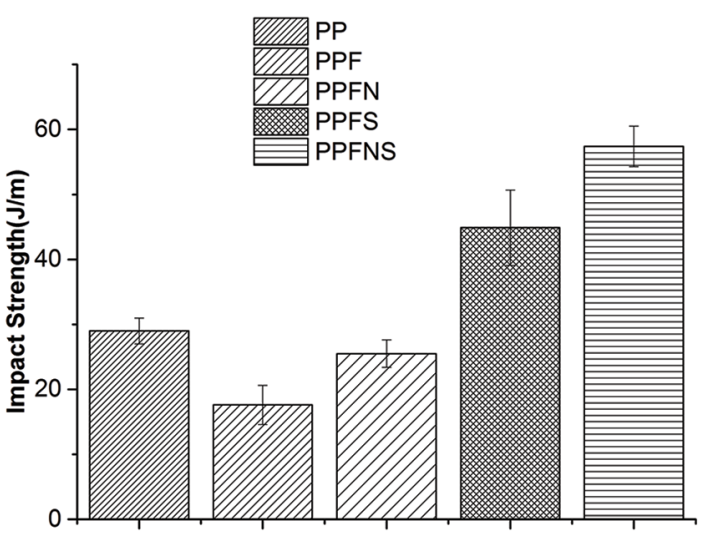

Figure 4: Impact strength $(\mathrm{J} / \mathrm{m})$ of composites specimens.
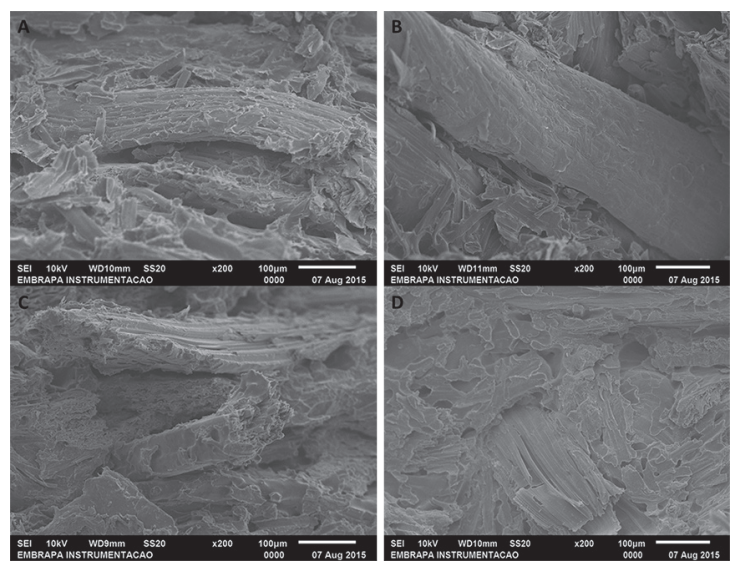

Figure 5: Scanning electron microscopy of fractured surfaces of composites (A) PPF (B) PPFN (C) PPFS (D) PPFNS.

\section{References}

1. Klason C, Kubat J. Cellulose in polymer composites. In: Salmen L, de Ruvo A, Seferis JC, Stark EB, editors. Composite systems from natural and synthetic polymers. Amsterdam: Elsevier Science; 1986.
2. Sanadi AR, Prasad SV, Rohatgi PK. Sunhemp fiber reinforced polyester composites: analysis of tensile and impact properties. Journal of Materials Science. 1986;21(12):4299-4304. http:// dx.doi.org/10.1007/BF01106545

3. Sanadi AR, Rowell RM, Caulfield DF. Reinforcing polypropylene with natural fibers. Plastics Engineering. 1994;50(4): 27-28.

4. Karnani R, Krishnan M, Narayan R. Biofiber-reinforced polypropylene composites. Polymer Engineering and Science. 1997;37(2):476-483.

5. Kalia S, Kaith BS, Kaur I. Pretreatments of natural fibers and their application as reinforcing material in polymer composites: a review. Polymer Engineering \& Science. 2012;49(7):1253-1272.

6. de Campos A, Tonoli GH, Marconcini JM, Mattoso LH, Klamczynski A, Gregorski KS, et al. Composite reinforced with treated sisal fibers: property, biodegradation and water-absorption. Journal of Polymers and the Environment. 2013; 21(1): 1-7. http:// dx.doi.org/10.1007/s10924-012-0512-8

7. Klemm D, Heublein B, Fink HP, Bohn A. Cellulose: fascinating biopolymer and sustainable raw material. Angewandte Chemie International Edition. 2005;44(22): 3358-3393. http://dx.doi. org/10.1002/anje. 200460587

8. Satyanarayana KG, Arizaga GG, Wypych F. Biodegradable composites based on lignocellulosic fibers: an overview. Progress in Polymer Science. 2009;34(9):982-1021.

9. Sanadi AR, Caulfield D. Thermoplastic polyolefins as formaldehyde free binders in highly filled lignocellulosic panel boards: using glycerine as a processing aid in kenaf fiber polypropylene boards. Materials Research. 2008;11(4):487-492. http://dx.doi. org/10;1590/S1516-14392009000400019

10. Markarian J. Outdoor living space drives growth in wood-plastic composites. Plastics Additives and Compounding. 2008:10(4): 20-25. http://dx.doi.org/10.1016/S1464-391X(08)70131-4

11. El-Haggar SM, Kamel MA. Wood plastic composites, advances in composite materials - analysis of natural and man-made materials. Rijeka, Croatia: Dr. Pavla Tesinova: Intech; 2011.

12. Clemons C, Sanadi AR. Instrumented impact testing of kenaf fiber reinforced polypropylene composites: effects of temperature and composition. Journal of Reinforced Plastics and Composites. 2007;26(15):1587-1602. http://dx.doi. org/10.1177/0731684407079663 
13. Jiang L, Wolcott MP, Zhang JW, Englund K. Flexural properties of surface reinforced wood/plastic deck board. Polymer Engineering and Science. 2007;47(3): 281-288. http://dx.doi.org/10.1002/pen.20705

14. Ku H, Wang H, Pattarachaiyakoop N, Trada M. A review on the tensile properties of natural fiber reinforced polymer composites. Composites Part B-Engineering. 2011; 42(4): 856-873. http:// dx.doi.org/10.1016/j.compositesb.2011.01.010

15. Bengtsson M, Le Baillif M, Oksman K. Extrusion and mechanical properties of highly filled cellulose fibrepolypropylene composites. Composites Part A-Applied Science and Manufacturing. 2007;38(8):1922-1931. http://dx.doi. org/10.1016/j.compositesa.2007.03.004

16. Dehghani A, Ardekani SM, Al-Maadeed MA, Hassan A, Wahit MU. Mechanical and thermal properties of date palm leaf fiber reinforced recycled poly (ethylene terephthalate) composites. Materials and Design. 2013;52(1): 841-848.

17. John MJ, Anandjiwala DR. Recent developments in chemical modification and characterization of natural fiber-reinforced composites. Polymer Composites. 2008; 29(2):187-107.

18. Vilay V, Mariatti M, Taib MR, Todo M. Effect of fiber surface treatment and fiber loading on the properties of bagasse fiber-reinforced unsaturated polyester composites. Composites Science and Technology. 2008;68(3-4):631-638. http://dx.doi. org/10.1016/j.compscitech.2007.10.005

19. Soleimani M, Tabil LG, Panigrahi S, Opoku A. The effect of fiber pretreatment and compatibilizer on mechanical and physical properties of flax fiber polypropylene composites. Journal Polymer Environment. 2008;16(1):74-82. http://dx.doi. org/10.1007/s10924-008-0102-y
20. Wu J, Yu D, Chan CM, Kim J, Mai YW. Effect of fiber pretreatment condition on the interfacial strength and mechanical properties of wood fiber/PP Composites. Journal of Applied Polymer Science. 2000;76(7):1000-1010. http://dx.doi.org/10.1002/ (SICI)1097-4628(20000516)76

21. Feng D, Caulfield DF, Sanadi AR. Effect of compatibilizer on the structure-property relationships of Kenaf-fiber/polypropylene composites. Polymer Composites. 2001;22(4):506-517. http:// dx.doi.org/10.1002/pc. 10555

22. Van Krevelen DW. Properties of polymers. 3rd ed. Amsterdam: Elsevier; 1990.

23. Cerqueira EF, Baptista CA, Mulinari DR. Mechanical behavior of polypropylene reinforced sugarcane bagasse fibers composites. Procedia Engineering. 2011;10: 2046-2051. http://dx.doi. org/10.1016/j.proeng.2011.04.339

24. Marques MF, Melo RP, Araujo RS, Lunz JN, Aguiar VO. Improvement of mechanical properties of natural fiberpolypropylene composites using successive alkaline treatments. Journal of Applied Polymer Science. 2015;132(12): http:// dx.doi.org/10.1002/APP.41710.

25. Guimarães JL, Frollini E, da Silva CG, Wypych F, Satyanarayana KG. Characterization of banana, sugarcane bagasse and sponge gourd fibers of Brazil. Industrial Crops and Products. 2009;30(3): 07-415. http://dx.doi.org/10.1016/j. indcrop.2009.07.013

26. Sanadi AR, Caulfield DF. Transcrystalline interphases in natural fiber-PP composites: effect of coupling agent. Composite Interfaces. 2000;7(1):31-43. 